\title{
Facial Palsy and Contemporary Reanimation Surgery: A Short Review
}

\author{
Hashem Shemshadi* (M.D., F.A.C.S) \\ Professor of Plastic and Reconstructive Surgery, University of Social Welfare and Rehabilitation Sciences, \\ Department of Clinical Sciences/Rofeideh Rehabilitation Hospital, Tehran, 19857-13834 Iran \\ * Corresponding author email: shemshadii@gmail.com \\ Received: 26 May 2020 / Revised: 04 June 2020 / Accepted: 23 June 2020 / Published: 27 June 2020
}

\begin{abstract}
The primary purpose of this mini-review article is to introduce modern issues of reanimation surgeries in patients with facial palsies. Modern methods of reanimation surgeries are discussed for mentioning patients ` benefits, and their more satisfactions and hopeful horizons for the future of such cases with facial palsies. Facial paralysis, associated to implementing new reanimation surgery techniques, is presenting new advanced methods of facial nerve palsy reforms, through reanimation surgeries. Facial palsy, which occur by a diversity of reasons, need to be evaluated for their etiologies and prepare a proper surgical plan for their reconstructions. Stroke, trauma, congenital, neoplasia, neurological, immunological, viral infections, and psychological reasons, are some potential causes of patients with facial palsies. Brief reviews were done, based on recent evidences` results in reanimation surgery practices. Due to any of above cited reasons, patients with facial palsies get physically and mentally disturbed and are willing to search ways, for solving their facial distressing problems. Consequently, mentioned patients are eagerly searching means to receive new available promotions to improve their facial palsies. In concluding, patients who undergo reanimation surgeries, if good results of their operations obtained, they will be motivated in gaining selfconfidence, self-care, self-respect and therefore getting a cumulative their effective social bond, and raising their quality of life, after reanimation operations.
\end{abstract}

Keywords: sophisticated, operation, rehabilitation

\section{Introduction}

Pathogenesis of facial palsies are different based on their variety of etiologies. In the past, no matter what was the cause of facial palsies, patients 'satisfactions after reanimation surgical reconstructions, were insignificant [1], [2]. Currently, by assessing the face and facial palsies and their appropriate surgical designs for new surgical techniques, more satisfactions are regained, after reanimation surgeries [3], [4], [5]. At the present time, more surgical methods are invented for facial palsies and gradually, possibilities of gaining better results in future are promising. Facial palsies may be due different causes of genetic, traumatic and neoplastic and iatrogenic episodes. Better results have been gained by different facial dimension analysis and more precise surgical plans, based on the cause, extend of damages in each patient with facial palsy[6], [7] . Congenital facial palsies which are detected after neonates ' birth, are discovered in delivery rooms during newborn health-checks [8]. This latter mentioned cause of neonatal facial palsy, is difficult to handle and have inadequate responses to reanimation surgeries. Also, congenital causes of facial palsies, show a less degree of recovery in long-term periods. In some cases, facial nerve may be completely absent after birth [9]. Head and neck traumas, are another common cause for facial paralysis. Facial zones instabilities due to trauma, cause soft and hard tissues get traumatized and patients find to have 
facial nerve damage. Trauma to facial zygomaticmaxillary sites, also may cause facial paralysis, [10]. Stroke is another cause of facial paralysis. Stroke at any type, not only result patients ' face and facial nerve, also result their extremities palsy as well. Brainstem stroke, results ipsilateral facial nerve palsy and contralateral limb hemiparesis due to vertebra-basilar neuroanatomical impairment [11]. Surgical trauma following cochlear implants, result facial palsy, immediately and/or long-time post operatively [12]. Middle ear surgeries may be attributed to the reactivation of patients 'previously viral infections, and may cause facial palsy [13]. This mentioned facial palsy, has been reported to be recovered, spontaneously. Viral infections may also directly affect patients ` facial nerve and thus lead to facial palsy. Viral cause in Bell`s palsy, if be treated promptly, higher number of patients will have their facial palsies, get dissolved freely [14]. Suggestions of bilateral facial palsy with the level of socioeconomic status, personal habits, mental status and poor hygiene have been considered [15] . Not all facial palsies respond to reanimation surgery, unless are highly chosen based on surgeons' decision for possible better results. Most of the above cited facial palsies, get recover and or end-up with a trivial palsy remaining. Tumors involving head and neck, may need patients to undergo extended operations. Post-surgical remainders, may leave facial palsies, and definitely need facial rehabilitation through reanimation surgeries, in order to minimize facial palsies into a better score. End-to-side facial nerve repair has been a promise in facial reanimation surgery [16] . Free gracilis muscle graft with cross facial nerve graft techniques, have been an advantage in selected patients by introducing patients proper reanimation surgeries [17] . Contemporary microvasculo-neuronal reanimation surgical techniques, have created new hopes for enhanced helps in needy patients in their facial nerve reanimation surgery implementations [18] . Recent advances in neuroanatomy and neurophysiology of variety of reanimation surgeries, in regard to creating a better surgical techniques, have promoted needy patients better facial nerve rehabilitation and thus have created more improvements in their quality of life [19]. In recent years, remarkable progresses have been made, in patients smile quality. This mentioned advancements have provided patients, better social communication [20]. Reanimation surgeries, may be monitor and follow-up by the surgeons, results a better post-operative period by electrophysiological tools, are highly valued. This above mentioned care, helps surgeons to validate their service and plan for a better future of their surgeries [21]. During any meticulous facial reanimation surgeries, exact considerations of facial nerves, may safety have preserved. In selected masseteric muscle flaps, in providing mastication functions, can be examined with electrophysiological, and electromyographically apparatuses [22], [23] . Patients with facial palsies might be under physical and mental pressures. Such mentioned patients might get impulsive, agitated and even depressed. Before implementing reanimation surgeries, patients psychological and psychiatric positions are advised to be checked [24]. In instances, patients who get successful results in their reanimation operations, are usually happy and are pleased after surgery. Cases with bilateral facial palsies need to be investigated thoroughly. In recent mentioned individuals, their underlying problems might be examined more seriously, because besides their facial nerve damages, their other cranial nerves might be involved. With good clinical and para-clinical investigations in before cited patients, if no other serious underlying problems found, their prognosis of their bilateral facial nerve palsies recoveries, are likely [25].

\section{Discussion}

The significant result of this brief review article, relies upon its up-to-date information, regarding to different facial palsies operations, which being applied with different new techniques of facial reanimation surgeries. Due to before mentioned causes, patients who are suffering facial palsies, it is thus important to discover a style of solving their problems sophistically. To elucidate before mentioned patients 'snags, operation techniques' types which possibly may be chosen by surgeons, need to be current. Past operations styles for reanimation surgeries, have undergone changes. 
Hashem Shemshadi, Int. Ann. Sci.; Vol. 9, Issue 1, pp: 141-144, 2020

Resulted facts in the past, showed facial reanimation surgery techniques, have undergone various bilateral useful alterations for patients and surgeons' safety both. Above mentioned fluctuations applied by surgeons who have tried to apt into surgical techniques, to have less postsurgical complications, less time of surgical durations and higher patient satisfactions. Through means of time elapsing, and new ways of performing novel techniques in correlated to facial reanimations, surgeons have learned how to manage and how to choose suitable facial palsy patients, for having proper operations with proper modern surgical skills. Previous surgical experiences disclosed, facial reanimation practices have given rise from simple regional soft tissue transfers, into a form of facial regional musculo-vasculo-neuronal advancement flaps, for reconstructing patients with facial palsies. Subsequently, facial reanimation surgery techniques moved from previous mentioned methods into great advances of free tissue graft transfers by miro-musculo-vasculo-neuronal methods. Sure, more advanced new techniques are expected in the future, designed by accredited university departments, to scheme teaching course plans, by distinguished professors in training residents and colleagues.

\section{Conclusion}

Patients with facial palsies need to be acknowledged and need to be considered in their society. Due to patients ' facial palsies, which have happened unexpectedly, they have less desires to communicate socially, because of their facial imbalances which have resulted their speech and facial smiling`s disarrays. Those above-mentioned problems, disturb proper animating functions for their pleasant facial expressions. Recent innovative facial reanimation surgeries, are highly advised for these agonized patients. Surgeons by selecting accurate patients and operate them with modern and suitable surgical techniques, their appearances may get changed accurately. After a possible successful operation, patient satisfactions and hopes increase and naturally will cause positive effects on their confidence in expecting a better tone of life, for their future.

\section{Competing Interests}

No conflict of interest is existed in developing this article

\section{How to Cite this Article:}

H. Shemshadi, "Facial Palsy and Contemporary Reanimation Surgery: A Short Review", Int. Ann. Sci., vol. 9, no. 1, pp. 141-144, Jun. 2020. doi:10.21467/ias.9.1.141-144

\section{References}

1. Wells, M.D. and R.T. Manktelow, Surgical management of facial palsy. Clin Plast Surg, 1990. 17(4): p. 645-53.

2. Broniatowski, M., P. Lavertu, and H.M. Tucker, The deep temporal nerve-orbicularis oculi muscle pedicle as a possible means for reanimation of the upper face. Ear Nose Throat J, 1990. 69(3): p. 140-4.

3. Ayoub, N.F., et al., Facial Paralysis and Communicative Participation: The Importance of Facial Symmetry at Rest. Ann Otol Rhinol Laryngol, 2020: p. 3489420912446.

4. Gyori, E., et al., Functional results after facial reanimation in iatrogenic facial palsy. Microsurgery, 2020. 40(2): p. 145-153.

5. Lee, Y.S., et al., Dual Coaptation of Facial Nerve Using Masseteric Branch of Trigeminal Nerve for Iatrogenic Facial Palsy: Preliminary Reports. Ann Otol Rhinol Laryngol, 2020. 129(5): p. 505-511.

6. Sakthivel, P., et al., Masseteric-Facial Nerve Anastomosis: Surgical Techniques and Outcomes-A Pilot Indian study. Indian J Otolaryngol Head Neck Surg, 2020. 72(1): p. 92-97.

7. Kim, M.J. and T.S. Oh, A nasolabial fold reset technique for enhancing midface lifts in facial reanimation: Threedimensional volumetric analysis. J Craniomaxillofac Surg, 2020. 48(2): p. 162-169.

8. Zhu, Y.H. and W.J. Han, [Congenital facial palsy]. Zhonghua Er Bi Yan Hou Tou Jing Wai Ke Za Zhi, 2019. 54(10): p. 787-791.

9. Agarwal, V., et al., Isolated Congenital Absence of Cranial Nerves: Report of Two Cases. Neuropediatrics, 2018. 49(6): p. 405-407.

10. Agarwal, P., et al., Facial Nerve Paralysis-A Rare Complication of Open Reduction of Zygomaticomaxillary Complex Fractures. J Oral Maxillofac Surg, 2018. 76(5): p. 1057 e1-1057 e5.

11. Alwood, B.T. and R.H. Dossani, Vertebrobasilar Stroke, in StatPearls. 2020: Treasure Island (FL).

12. Alzhrani, F., T. Lenarz, and M. Teschner, Facial palsy following cochlear implantation. Eur Arch Otorhinolaryngol, 2016. 273(12): p. 4199-4207.

13. Zwick, O.M. and S.R. Seiff, Supportive care of facial nerve palsy with temporary external eyelid weights. Optometry, 2006. 77(7): p. 340-2.

14. Yoo, M.C., et al., Evaluation of Factors Associated With Favorable Outcomes in Adults With Bell Palsy. JAMA Otolaryngol Head Neck Surg, 2020.

15. Bruins, T.E., et al., Association of Socioeconomic, Personality, and Mental Health Factors With HealthRelated Quality of Life in Patients With Facial Palsy. JAMA Otolaryngol Head Neck Surg, 2020. 
16. Konofaos, P., S. Bassilios Habre, and R.D. Wallace, End-to-Side Nerve Repair: Current Concepts and Future Perspectives. Ann Plast Surg, 2018. 81(6): p. 736-740.

17. Kim, M.J., et al., Comparative Study of 2 Different Innervation Techniques in Facial Reanimation: Crossface Nerve Graft-Innervated Versus Double-Innervated Free Gracilis Muscle Transfer. Ann Plast Surg, 2020. 84(2): p. 188-195.

18. Gonzalez-Garcia, J.A., et al., Porcine experimental model for gracilis free flap transfer to the head and neck area with novel donor site description. J Plast Reconstr Aesthet Surg, 2020. 73(1): p. 111-117.

19. Gibelli, D., et al., Three-dimensional assessment of restored smiling mobility after reanimation of unilateral facial palsy by triple innervation technique. Int J Oral Maxillofac Surg, 2020. 49(4): p. 536-542.

20. Watanabe, Y., et al., One-stage free transfer of latissimus dorsi-serratus anterior combined muscle flap with dual innervation for smile reanimation in established facial paralysis. J Plast Reconstr Aesthet Surg, 2020.

21. Baba, S., K. Kondo, and T. Yamasoba, Electrophysiological Evaluation of the Facial Muscles in Congenital Unilateral Lower Lip Palsy. Otol Neurotol, 2018. 39(1): p. 106-110.

22. Telich-Tarriba, J.E. and A. Cardenas-Mejia, Electromyographic evaluation of the facial and motor donor nerves before facial reanimation surgery in Moebius syndrome. Cir Cir, 2020. 88(1): p. 71-75.

23. Telich-Tarriba, J.E., et al., Changes in Electrical Activity of the Masseter Muscle and Masticatory Force after the Use of the Masseter Nerve as Donor in Facial Reanimation Surgery. Indian J Plast Surg, 2020. 53(1): p. 59-63.

24. Krishnan, K.G., G. Schackert, and V. Seifert, Outcomes of microneurovascular facial reanimation using masseteric innervation in patients with long-standing facial palsy resulting from cured brainstem lesions. Neurosurgery, 2010. 67(3): p. 663-74; discussion 674.

25. Jung, J., et al., Bilateral facial palsy. Acta Otolaryngol, 2019. 139(10): p. 934-938.
Publish your research article in AIJR journals-

* Online Submission and Tracking

* Peer-Reviewed

* Rapid decision

* Immediate Publication after acceptance

* Articles freely available online

* Retain full copyright of your article.

Submit your article at journals.aijr.in

\section{Publish your books with AIJR publisher-}

* Publish with ISBN and DOI.

* Publish Thesis/Dissertation as Monograph.

* Publish Book Monograph.

* Publish Edited Volume/ Book.

* Publish Conference Proceedings

* Retain full copyright of your books.

Submit your manuscript at books.aijr.org 